EPJ Web of Conferences 110,01013 (2016)

DOI: $10.1051 /$ epjconf/201611001013

C) Owned by the authors, published by EDP Sciences, 2016

\title{
EVAPORATION AND VAPOR FORMATION OF GRAPHITE SUSPENSIONS BASED ON WATER IN A HIGH- TEMPERATURE GAS ENVIRONMENT: AN EXPERIMENTAL INVESTIGATION
}

\author{
Anastasia G. Borisova ${ }^{1}$, Maxim V. Piskunov ${ }^{1,}$, Kirill A. Rybatskyy $^{1}$ \\ ${ }^{1}$ National Research Tomsk Polytechnic University, 634050 Tomsk, Russia
}

\begin{abstract}
We performed an experimental research on evaporation and vapor formation of water droplets containing large ( $2 \mathrm{~mm}$ in size) and small $(0.05 \mathrm{~mm}$ and $0.2 \mathrm{~mm}$ in diameter) graphite inclusions, when heated in a high-temperature gas environment. We applied a highspeed (up to $10^{4} \mathrm{fps}$ ) video recording to establish mechanisms of the processes considered. Moreover, we revealed the positive influence of addition of small graphite inclusions on intensifying the evaporation of heterogeneous suspension droplets. In addition, we made the assumption on the formation of vapor layer around the 10 and $15 \mu 1$ suspension droplets, as well as its negative influence on the lifetimes of suspension droplets $\tau_{\mathrm{h}}$ (increasing the times) in a high-temperature gas environment.
\end{abstract}

\section{Introduction}

Nowadays, the application of heterogeneous liquids in various branches of industry, such as nuclear power engineering (as coolant in cooling systems), the heat power engineering (as the heat-transfer fluid), chemical and petrochemical industries proves its efficiency (for example, [1]). In the published research results on intensifying the thermal processes, the authors note the improved heat-exchange properties of heterogeneous liquids $[2,3]$. The greatest interest is to study phase changes at the solid/liquid interfaces, as well as to determine the scale of joint influence of evaporation and vapor formation in the considered heterogeneous systems. Moreover, we emphasize that in the conditions of absence of the theoretical foundation describing the phase changes of homogeneous and heterogeneous liquids when heated in a high-temperature (1000-1100 K) environments, the performance of experimental research in the given field is appropriate. The analysis and processing of the obtained empirical data will allow improving the existing heterogeneous high-temperature technologies (for example, [4-6]).

The purpose of the present work is to determine the influence of addition of the finely dispersed graphite particles into water droplets on the intensification of their evaporation.

${ }^{a}$ Corresponding author: piskunovmv@tpu.ru

This is an Open Access article distributed under the terms of the Creative Commons Attribution License 4.0, which permits unrestricted use, distribution, and reproduction in any medium, provided the original work is properly cited. Article available at nttp://www.ep|-conferences.org or nitp://dx.dol.org/10.1051/ep|cont/201611001013 


\section{Experimental setup and procedure}

We carry out the experimental research by the setup illustrated in Fig. 1. Performing the experiments, we use the high-speed (to $10^{5}$ frames per second) video cameras for determining time characteristics and visualizing features of the processes under consideration. The experimental procedure is mainly similar to the one applied in $[7,8]$.

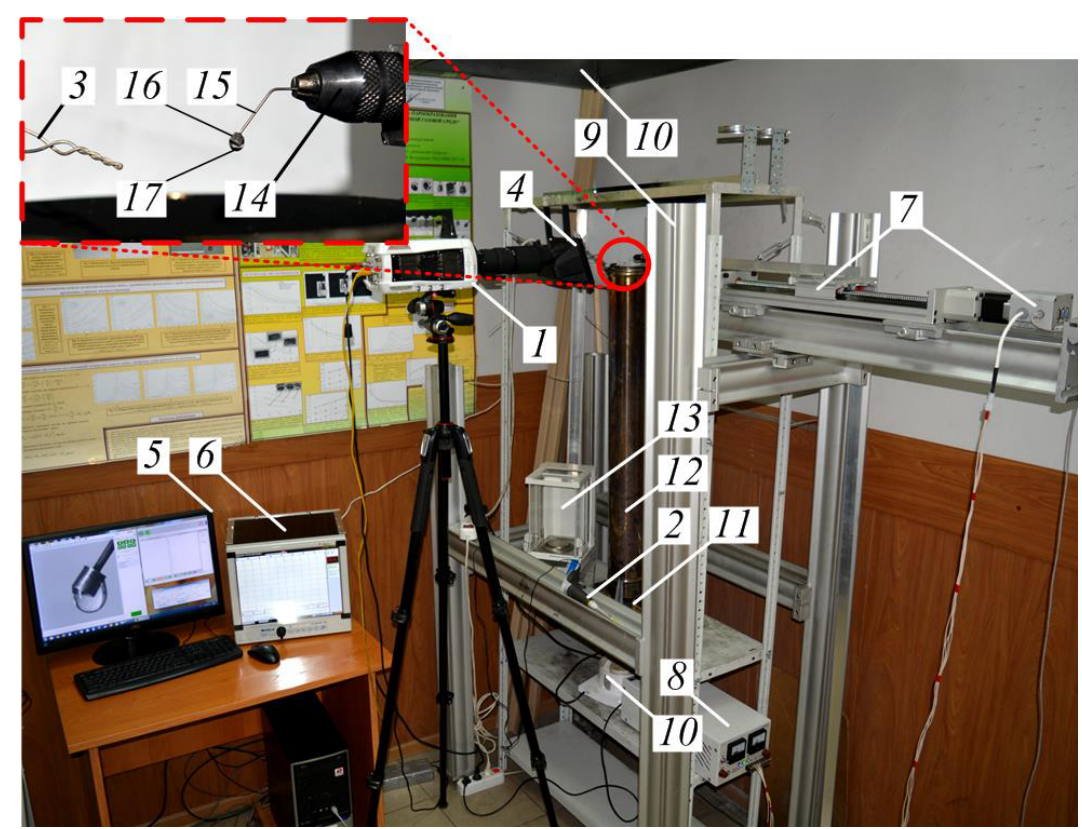

Figure 1. Physical configuration of the experimental setup: 1 - high-speed camera, 2 - dosing device, 3 - type $\mathrm{K}$ thermocouple, 4 - spotlight, 5 - personal computer (PC), 6 - temperature registration, 7 - moving mechanism, 8 - electric power supply of moving mechanism, 9 - mount, 10 - air flow system 11 - burner, 12 - metallic cylinder, 13 - weighing system, 14 - guideway to fix a ceramic rod, 15 - ceramic rod, 16 - large graphite inclusion, 17 - droplet of water / suspension.

In our paper, to determine the influence of addition of small graphite inclusions into water droplets on the intensification of their evaporation, we use the four types of suspensions and water without additives: No. 1 - size of the graphite particles $d_{p}=0.05 \mathrm{~mm}$, mass concentration of the graphite particles in water $\gamma_{p}=1 \%$; No. $2-d_{p}=0.05 \mathrm{~mm}, \gamma_{p}=2 \%$; No. $3-d_{p}=0.2 \mathrm{~mm}, \gamma_{p}=1 \%$; No. $4-d_{p}$ $=0.2 \mathrm{~mm}, \gamma_{p}=2 \%$; No. 5 - pure water. Before carrying out the experiment, a water droplet of 5,10 or $15 \mu \mathrm{l}$ in volume lowers on a large graphite inclusion in the shape of cube ( $2 \mathrm{~mm}$ in size). Previously, we weigh each large graphite inclusion using system 14 . The mass of the graphite inclusions is $0.012 \pm 0.002 \mathrm{~g}$.

In this research, the obligatory conditions of each experiment are a full coating of graphite inclusion 16 by droplet of water / suspension 17 (see inset of Fig. 1) and regulation of the initial inclusion temperature. These conditions are achieved by immersion of inclusion 16 during $2 \mathrm{~s}$ in a vessel with water (temperature is about $298 \mathrm{~K}$ ) before carrying out each test. The mass of liquid remaining on the graphite particles (after the immersion) is $0.002 \mathrm{~g}$ on average and taken into account when processing the results of experiments.

Under the identical conditions (size, shape, mass of large graphite inclusions, temperature of combustion products and their velocities, initial mass for the droplets of suspensions / water covering fully a large inclusion), we perform the three series of experiments consisting of 6-8 tests.

To control the flow velocities of high-temperature gas $U_{\mathrm{g}}$, we use the digital anemometer. The gas velocities $U_{\mathrm{g}}$ keeps at $1.5-2 \mathrm{~m} / \mathrm{s}$ by fan and exhaust ventilation 10 . The given velocity is acceptable for providing the following conditions: keeping the integrity of a heterogeneous droplet when heated 
in a high-temperature gas flow and supporting the required height of flame (along the length of the metal cylinder 12).

The recording by high-speed video camera 1 and the further processing of the video material using Phantom Camera Control software allow determining lifetimes $\tau_{\mathrm{h}}$ of the heterogeneous liquid droplets, when heated in a high-temperature gas environment. For this task, the sample rate is 400-600 fps. Moreover, we apply the high-speed video recording to study in detail the vapor formation of the water droplets (containing the finely dispersed graphite particles) at the graphite / liquid and liquid / gas interfaces. For this task, the sample rate is $10^{3}-10^{4} \mathrm{fps}$.

The technical ethanol is used as a combustible liquid. It is filled in burner 11 equipped with the four holes, which provide the required air inflow in the burning area. In addition, we note that the volume of combustible liquid in each series of experiments is constant and equals to $60 \mathrm{ml}$. The ethanol in such volume and at the abovementioned velocity of gas flow burns about $300 \mathrm{~s}$. It is enough to carry out the one series of experiments consisting of 6-8 tests depending on the mass of the water / suspension droplet.

The monitoring of gas temperature $T_{\mathrm{g}}$ is carried out by the type $\mathrm{K}$ thermocouple 3 . It is fixed in the area, in which the heterogeneous liquid droplets interact with the high-temperature combustion products (see inset of Fig. 1). The thermocouple data register using device 6 . The further data processing on the gas temperature $T_{\mathrm{g}}$ is carried out by personal computer 5 .

The main steps of the procedure are:

1. Ignition of the combustible liquid.

2. Moving the heterogeneous liquid droplet fixed on the ceramic rod in a high-temperature gas by mechanism 7.

3. Activation of the high-speed video recording; determination of the initial time of heterogeneous liquid droplet evaporation $\tau_{\mathrm{h} 0}$.

4. Moving the graphite inclusion back from a high-temperature gas, its cooling and full coating by water; lowering the next droplet of water / suspension on the inclusion.

5. Analysis of lifetimes $\tau_{\mathrm{h}}$ after carrying out a series of tests.

6. Determination of the change ranges in the gas temperature $T_{\mathrm{g}}$ by the initial times of heterogeneous liquid droplet evaporation $\tau_{\mathrm{h} 0}$ and taking into account the lifetimes revealed by the recorded video materials.

Errors on lifetime $\tau_{\mathrm{h}}$ determination are less than $10^{-3} \mathrm{~s}$. Random (characterized by repeatability of measurement results) $T_{\mathrm{g}}$ and $\tau_{\mathrm{h}}$ errors are $7 \%$.

\section{Results and discussion}

Fig. 2 illustrates the lifetimes $\tau_{\mathrm{h}}$ of $5 \mu \mathrm{l}(a), 10 \mu \mathrm{l}(b)$ and $15 \mu \mathrm{l}(c)$ heterogeneous liquid droplets. We compare the lifetimes for the droplets with $1 \%$ (2) and $2 \%$ (3) mass concentrations of small (diameter of $0.05 \mathrm{~mm}$ ) graphite particles, as well as without additives (1). We remember that all the considered liquid droplets contain the large graphite inclusions mentioned above. Fig. 2, a shows that in the whole considered range of heating temperatures, we can observe the reduction of lifetimes for heterogeneous liquid droplets by addition of small graphite inclusions. Moreover, the liquid droplets with $2 \%$ mass concentration of graphite inclusions have the minimum lifetimes $\tau_{\mathrm{h}}$. We note that the differences in lifetimes $\tau_{\mathrm{h}}$ for different mixtures (Fig. 2, a, curves $-1,2$ and 3) decrease when increasing the gas temperature. Thus, we can say about intensifying the evaporation of $5 \mu$ l water droplets containing small graphite inclusions (droplets of graphite suspensions). Fig. 2, $b$ illustrates that at a low $(350 \mathrm{~K})$ temperature, the lifetime distribution is similar to the one presented in Fig. 2, $a$. Furthermore, the difference between the lifetimes for the droplets of suspensions (curves -2 and 3 ) and water (curve -1 ) is significant (up to $50 \%$ ). This difference decreases significantly at an average $(600 \mathrm{~K})$ temperature (up to $30 \%)$, but at a high $(850 \mathrm{~K})$ temperature, the difference is minimal $(10-$ $15 \%$ ). Moreover, we observe that the droplet of suspension with $1 \%$ graphite inclusion concentration has the minimum lifetime. The tendency is enhanced when increasing the volume of liquid droplets to $15 \mu \mathrm{l}$ (Fig. 2,c). Now, we note the negative effect from the addition of small graphite inclusions, 
when the droplets of suspensions evaporate at a high $(850 \mathrm{~K})$ temperature. In particular, the droplets of suspensions evaporate longer at $10-12 \%$ than water droplets. We suppose that such phenomenon is caused by formation of heat-insulating vapor layer (heat conductivity factor for the water vapor is lower than for water) near the surface of the considered 10 and $15 \mu 1$ heterogeneous droplets. It occurs due to the activation of the vapor formation mechanism at the small graphite inclusion / water interfaces at a high $(850 \mathrm{~K})$ heating temperature. In particular, due to the low heat conductivity of the water vapor, the heating-up of the heterogeneous droplet of suspension becomes longer in comparison with the heating-up of the heterogeneous water droplet (see inset of Fig. 2, c). As the result, the lifetime $\tau_{\mathrm{h}}$ for the droplets of suspensions increases.

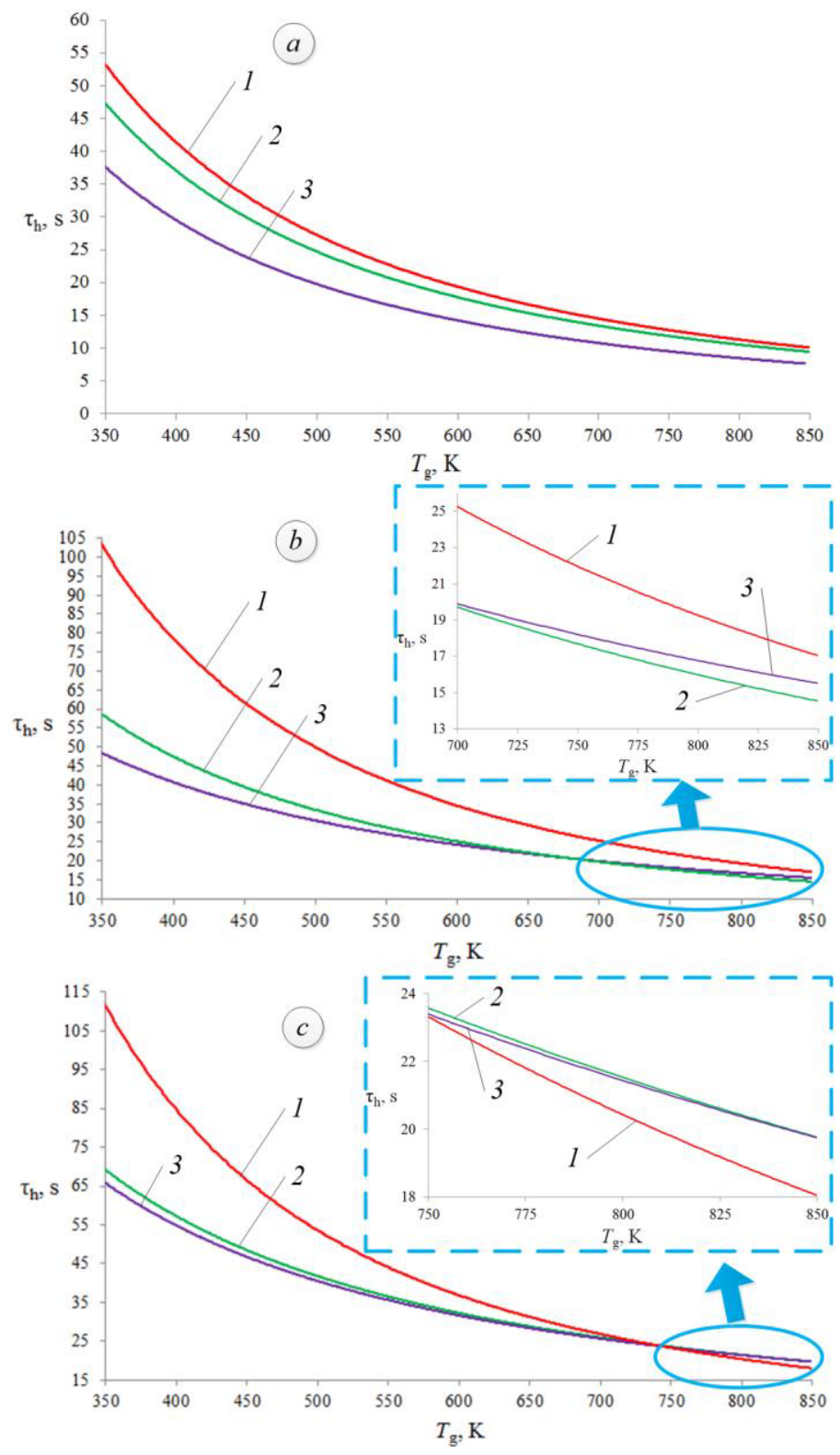

Figure 2. Lifetimes for the $5 \mu \mathrm{l}(a), 10 \mu \mathrm{l}(b)$ and $15 \mu \mathrm{l}(c)$ heterogeneous liquid droplets with $1 \%(2)$ and $2 \%(3)$ mass concentrations of the small graphite particles $(0.05 \mathrm{~mm}$ in diameter), as well as without the graphite particles (1). 
In addition, we have carried out the experiments using the suspensions with the graphite particle size $d_{p}=0.2 \mathrm{~mm}$ and mass concentration $\gamma_{p}=1 \%$ and $2 \%$. When analyzing the results of these experiments, we have also used the hypothesis described above.

The obtained results contribute the development of the modern concepts [1-9] on the mechanisms of phase changes in the high-temperature heterogeneous liquid flows and approaches for enhancing their heat-exchange properties by the addition of different additives. We consider that the detailed study of vapor formation at the solid/liquid interfaces, in particular, the processes of formation and evolution of the vapor bubbles is appropriate to explain and extend our hypothesis.

\section{Conclusion}

We have revealed that the $5 \mu 1$ heterogeneous droplets of suspension with the $2 \%$ mass concentration of small graphite inclusions evaporates faster (up to 50\%) than the heterogeneous water droplet with the same volume. However, when increasing the volume of a droplet of suspension, we have revealed the negative effect from the addition of small graphite inclusions (lifetimes $\tau_{\mathrm{h}}$ for the droplets of suspensions have increased at $10-12 \%$ in comparison with the lifetimes $\tau_{\mathrm{h}}$ for the heterogeneous water droplets). We have proposed the hypothesis that the heat-insulating vapor layer can be formed near the surface of the heterogeneous liquid droplets evaporating in a high-temperature $(850 \mathrm{~K})$ gas.

This work was supported by the grant of the President of the Russian Federation (MD-2806.2015.8).

\section{References}

1. X.-Q. Wang, A.S. Mujumdar, Int. J. Therm. Sci., 46, 1 (2007)

2. D.K. Agarwal, A. Vaidyanathan, S. Sunil Kumar, Exp. Therm. Fluid Sci., 71, 126 (2016)

3. W.H. Azmi, K.V. Sharma, R. Mamat, G. Najafi, M.S. Mohamad, Renewable Sustainable Energy Rev., 53, 1046 (2016)

4. S.K. Verma, A.K. Tiwari, Energy Convers. Manage., 100, 324 (2015)

5. R.S. Volkov, M.V. Piskunov, G.V. Kuznetsov, P.A. Strizhak, J. Heat Transfer, 138, 1 (2016)

6. M.V. Piskunov, A.A. Shcherbinina, P.A. Strizhak, Procedia Soc. Behav. Sci., 206, 315 (2015)

7. G.V. Kuznetsov, M.V. Piskunov, P.A. Strizhak, Int. J. Heat Mass Transf., 92, 360 (2016)

8. I.S. Anufriev, G.V. Kuznetsov, M.V. Piskunov, P.A. Strizhak, M.Yu. Chernetskii, Tech. Phys. Lett., 41, 810 (2015)

9. R. Saidur, K.Y. Leong, H.A. Mohammad, Renewable Sustainable Energy Rev., 15, 1646 (2011) 